\title{
Comparative genomics reveals signature regions used to develop a robust and sensitive multiplex TaqMan real-time qPCR assay to detect the genus Dickeya and Dickeya dianthicola
}

\author{
Shefali Dobhal ${ }^{1}$, Gamze Boluk ${ }^{1}$, Brooke Babler ${ }^{2}$, Michael J. Stulberg ${ }^{3}$, John Rascoe ${ }^{3}$, Mark \\ Nakhla $^{3}$, Toni A. Chapman ${ }^{4}$, Alex B. Crockford ${ }^{2}$, Michael Melzer ${ }^{1}$, Anne M. Alvarez ${ }^{1}$ and \\ Mohammad Arif ${ }^{1 *}$
}

\begin{abstract}
${ }^{1}$ Department of Plant and Environmental Protection Sciences, University of Hawaii at Manoa, Honolulu, HI. ${ }^{2}$ Department of Plant Pathology, Wisconsin Seed Potato Lab, University of Wisconsin-Madison, WI. ${ }^{3}$ Science and Technology, Plant Protection and Quarantine, Animal and Health Inspection Service, United States Department of Agriculture, Beltsville, MD. ${ }^{4}$ Biosecurity and Food Safety, NSW Department of Primary Industries, Elizabeth Macarthur Agricultural Institute, Menangle, NSW, Australia.
\end{abstract}

*Corresponding author: email arif@hawaii.edu; Phone 001-8089567765

\begin{abstract}
Aims

Dickeya species are high consequence plant pathogenic bacteria listed among the quarantine pathogens of the European Union; associated with potato disease outbreaks and subsequent economic losses worldwide. Early, accurate, and reliable detection of Dickeya spp. is needed to prevent establishment and further dissemination of this pathogen. Therefore, a multiplex TaqMan qPCR was developed for sensitive detection of Dickeya spp. and specifically, D. dianthicola.
\end{abstract}

\section{Methods and Results}

A signature genomic region for the genus Dickeya $(\mathrm{mglA} / \mathrm{mglC})$ and unique genomic region for $D$. dianthicola (alcohol dehydrogenase) were identified using a whole genome based comparative genomics approach. The developed multiplex TaqMan qPCR was validated using extensive inclusivity and exclusivity panels, and naturally/artificially infected samples to confirm broad range detection capability and specificity. Both sensitivity and spiked assays showed detection limit of $10 \mathrm{fg}$ DNA.

\section{Conclusion}

The developed multiplex assay is sensitive and reliable to detect Dickeya spp. and D. dianthicola with no false positives or false negatives. It was able to detect mixed infection from naturally and artificially infected plant materials.

\section{Significance and Impact}

The developed assay will serve as a practical tool for screening of propagative material, monitoring the presence and distribution, and quantification of target pathogens in a breeding program. The assay also has applications in routine diagnostics, biosecurity and microbial forensics. 


\section{Introduction}

The genus Dickeya belongs to the family Enterobacteriaceae and is comprised of pectinolytic Gram negative plant pathogenic bacteria, responsible for the soft rot diseases worldwide. Due to their association with catastrophic diseases, Dickeya species have been listed among the top ten most destructive bacterial plant pathogens (Mansfield et al. 2012). Soft rot Enterobacteria are also associated with the most serious problems facing potato production worldwide. The impact of soft rot disease varies from country to country; in the Netherlands, the annual estimated losses are around $€ 30$ million per year, while in Israel, potato yield losses of 20-25\% have been observed. (Tsror (Lahkim) et al. 2009; Raoul des Essarts et al. 2016; Buttimer et al. 2017).

The genus Dickeya originally included six species: D. chrysanthemi, D. dadantii, D. dieffenbachiae, D. dianthicola, D. paradisiaca, and D. zeae (Samson et al. 2005). Later, D. dieffenbachiae was reclassified as a subspecies of $D$. dadantii based on the DNA-DNA hybridization and phylogenetic analyses (Brady et al. 2012). Dickeya now has eight species including, D. solani (Van der Wolf et al. 2014), D. aquatica (Parkinson et al. 2014) and the recently described D. fangzondai (Tian et al. 2016). Dickeya species have a broad host range, infecting both monocots and dicots (Ma et al. 2007). They are responsible for soft rots of vegetables and ornamentals, resulting in high economic losses in various geographical locations worldwide (Van Vaerenbergh et al. 2012).

Symptoms caused by Dickeya spp. are more severe in high moisture and temperature environments (Czajkowski et al. 2009). Infected plants show stunting, chlorosis, wilting, black discoloration and soft rot, which begins at the stem base and progresses upward. Once infection has occurred, the pathogen colonizes the vascular tissues and moves throughout the plant (Raoul des Essarts et al. 2016); severe infections lead to whole plant collapse. Latent infections can result in severe losses during storage, especially in warehouses that lack refrigeration facilities (Laurila et al. 2008). In recent years, D. dianthicola has emerged as one of the most important pathogens infecting potatoes worldwide, and symptoms resemble those of blackleg caused by Pectobacterium species (Boluk and Arif 2019). Due to high economic impact in the European potato growing countries, $D$. dianthicola (syn. Erwinia chrysanthemi pv. dianthicola) has been listed in the EPPO A2 List of pests recommended for regulation as quarantine pests A2/53 (Pg 8); http://archives.eppo.int/EPPOStandards. At present, neither resistant varieties nor effective physical, chemical or biological controls have been reported to manage $D$. dianthicola diseases under field conditions (Czajkowski et al. 2014). Only preventive measures are recommended, which include planting certified seeds, eradicating contaminated plant materials, screening for latent infections, monitoring appropriate storage conditions and inspecting fields (Motyka et al. 2017). Therefore, early, accurate and sensitive detection of Dickeya species is important to identify inoculum sources before they become a problem.

Several assays have been reported for detection of Dickeya from infected samples including selective and semi-selective media (Hayman et al. 2001; Helias et al. 2012), microscopic observations, and biochemical and serological identification methods (Czajkowski et al. 2015; Motyka et al. 2017). Detection based on molecular methods such as PCR, quantitative PCR and loop-mediated isothermal amplification (LAMP) are implemented routinely due to their high sensitivity, speed, specificity, accuracy, discriminatory ability and reproducibility (Ouyang et al. 2013; Czajkowski et al. 2015; Ocenar et al. 2019). TaqMan probe-based qPCR assays are more accurate, sensitive and reliable for detection of a pathogen (Arif et al. 2014). Moreover, addition 
of 5' AT-rich flap sequences enhanced the reaction efficiency and sensitivity of multiplex TaqMan qPCR (Arif and Ochoa-Corona 2013; Larrea et al. 2019). TaqMan qPCR assays have been reported for the detection of $D$. solani using fliC gene, and $D$. solani and $D$. dianthicola using targets based on computational primer prediction pipeline for draft bacterial genomic sequences (Vaerenbergh et al. 2012; Pritchard et al. 2013). In 2014, van der Wolf et al. reported dnaX genebased TaqMan qPCR assay for detection of Dickeya spp. and described a number of primer pairs to detect different Dickeya sp. TaqMan qPCR with the probes labelled with different fluorogenic dyes enables simultaneous detection of multiple pathogens or pests in a single tube (Arif et al. 2015). Multiplex TaqMan can be very useful for detection of different Dickeya species, which produces nearly indistinguishable disease symptoms without compromising the sensitivity and specificity of the assay.

In this study, we have presented a multiplex TaqMan qPCR for sensitive and simultaneous detection of genus Dickeya and $D$. dianthicola. The developed multiplex TaqMan qPCR was validated in the lab extracted DNA from purified cultures and naturally infected potato samples. Comparative genomics using Mauve identified signature genomic regions; the gene $\mathrm{mglA} / \mathrm{mglC}$ region was used to design the primers/probe for the genus Dickeya, while the alcohol dehydrogenase gene was used for designing the primers targeting $D$. dianthicola. The developed assay has applications in farm management, seed certification, biosecurity and to discover new reservoir hosts.

\section{Materials and Methods}

\section{Bacterial strains, growth conditions and plant inoculations in greenhouse}

Thirty-three Dickeya strains, collected from different geographical locations worldwide, were used in an inclusivity panel (Table 1). Strain numbers prefixed with "A" were obtained from the Pacific Bacterial Collection (University of Hawaii at Manoa). In addition, 34 bacterial strains from other genera comprising closely related species from different genera, were included in an exclusivity panel (Table 1). All strains were stored at $-80^{\circ} \mathrm{C}$. For culturing, strains were streaked on 2,3,5triphenyl- tetrazolium chloride sucrose medium (TZC-S: peptone $10 \mathrm{~g} \mathrm{l}^{-1}$, sucrose $5 \mathrm{~g} \mathrm{l}^{-1}, 0.001 \%$ TZC and agar $\left.17 \mathrm{~g} \mathrm{l}^{-1}\right)$ (Norman and Alvarez 1989). The plates were incubated at $26^{\circ} \mathrm{C}\left( \pm 2^{\circ} \mathrm{C}\right)$ overnight; single colonies were streaked on YSC medium (yeast extract $10 \mathrm{~g} \mathrm{l}^{-1}$, dextrose $20 \mathrm{~g} \mathrm{l}^{-1}$, calcium carbonate $20 \mathrm{~g} \mathrm{l}^{-1}$ and agar $\left.17 \mathrm{~g}^{-1}\right)$ and incubated at $26^{\circ} \mathrm{C}\left( \pm 2^{\circ} \mathrm{C}\right)$ overnight; these plates were used for DNA isolation.

Table 1: Bacterial strains used for validation of multiplex TaqMan real-time qPCR developed and validated for specific detection of Dickeya and D. dianthicola.

\begin{tabular}{|c|c|c|c|c|c|c|c|c|}
\hline Microorganism & $\begin{array}{c}\text { Strain } \\
\text { number }\end{array}$ & Other ID & $\begin{array}{l}\text { Geographic } \\
\text { location }\end{array}$ & Host & $\begin{array}{c}\text { Identity } \\
\text { confirmation }\end{array}$ & $\begin{array}{c}\text { Accession } \\
\text { no. }\end{array}$ & \multicolumn{2}{|c|}{ Mean $\mathbf{C} t \pm$ SD } \\
\hline $\begin{array}{l}\text { Inclusivity Panel } \\
\text { Dickeya zeae }\end{array}$ & A6056 & 3 leaf & Hawaii, USA & $\begin{array}{l}\text { Ananas } \\
\text { comosus }\end{array}$ & dnaA F1/R1 & MH453535 & - & $17.93 \pm 0.0$ \\
\hline D. zeae & A5422 & CFBP2052 & USA & Zea mays & dnaA F1/R1 & MH453537 & - & $17.10 \pm 0.04$ \\
\hline D. zeae & A6069 & CFBP1277 & USA & Z. mays & dnaA F1/R1 & MK208960 & - & $18.49 \pm 0.09$ \\
\hline D. zeae & A5423 & CFBP6466 & Martinique & A. comosus & dnaA F1/R1 & MH453536 & - & $17.68 \pm 0.10$ \\
\hline D. dadantii & A5642 & CFBP 3855 & France & Saintpaulia & dnaA F1/R1 & MH453542 & - & $16.17 \pm 0.03$ \\
\hline D. dadantii & A5416 & CFBP1269 & $\begin{array}{l}\text { Africa (Comoro } \\
\text { Isle) }\end{array}$ & $\begin{array}{l}\text { Pelargonium } \\
\text { capitatum }\end{array}$ & dnaA F1/R1 & MK208944 & - & $16.21 \pm 0.20$ \\
\hline D. dadantii & A5643 & CFBP 6467 & Martinique & Musa sp. & dnaA F1/R1 & MK208950 & - & $17.92 \pm 0.21$ \\
\hline
\end{tabular}


bioRxiv preprint doi: https://doi.org/10.1101/847590; this version posted November 20, 2019. The copyright holder for this preprint (which was not certified by peer review) is the author/funder, who has granted bioRxiv a license to display the preprint in perpetuity. It is made available under aCC-BY-NC-ND 4.0 International license.

\begin{tabular}{|c|c|c|c|c|c|c|c|c|}
\hline D. dadantii & A5576 & PRI 2120 & Comoros, Africa & P. capitatum & dnaA F1/R1 & MK208948 & - & $16.82 \pm 0.05$ \\
\hline D. zeae & A6066 & CFBP1889 & Malaysia & A. comosus & dnaA F1/R1 & MK208958 & - & $19.01 \pm 0.01$ \\
\hline D. zeae & A6067 & CFBP1890 & Malaysia & A. comosus & dnaA F1/R1 & MK208959 & - & $18.81 \pm 0.10$ \\
\hline D. dadantii & A5419 & CFBP2051 & USA & $\begin{array}{l}\text { Dieffenbachia } \\
\text { sp. }\end{array}$ & dnaA F1/R1 & MK208945 & - & $14.30 \pm 0.06$ \\
\hline D. dadantii & A6060 & CFBP3698 & Cuba & Musa sp. & dnaA F1/R1 & MK208956 & - & $13.89 \pm 0.04$ \\
\hline D. dadantii & A6061 & CFBP1247 & USA & $\begin{array}{l}\text { Dieffenbachia } \\
\text { picta }\end{array}$ & dnaA F1/R1 & MK208957 & - & $18.91 \pm 0.05$ \\
\hline D. chrysanthemi & A5641 & CFBP 1270 & Denmark & $\begin{array}{l}\text { Parthenium } \\
\text { argentatum }\end{array}$ & dnaA F1/R1 & MH453539 & - & $30.84 \pm 0.11$ \\
\hline D. chrysanthemi & A5415 & CFBP2048 & USA & $\begin{array}{l}\text { Chrysanthemu } \\
m\end{array}$ & dnaA F1/R1 & MH453538 & - & $20.58 \pm 0.15$ \\
\hline D. solani & A5582 & PRI 2188 & Israel & $\begin{array}{l}\text { Solanum } \\
\text { tuberosum }\end{array}$ & dnaA F1/R1 & MH453541 & - & $19.01 \pm 0.11$ \\
\hline D. solani & A5581 & PRI 2187 & Israel & S. tuberosum & dnaA F1/R1 & MH453540 & - & $14.26 \pm 0.02$ \\
\hline D. dianthicola & A5418 & CFBP1200 & UK & $\begin{array}{l}\text { Dianthus } \\
\text { caryophyllus }\end{array}$ & dnaA F1/R1 & MK208961 & $15.05 \pm 0.02$ & $15.05 \pm 0.02$ \\
\hline D. dianthicola & PL22 & GBp1A & Hawaii, USA & S. tuberosum & dnaA F1/R1 & MK189269 & $22.57 \pm 0.02$ & $22.17 \pm 0.02$ \\
\hline D. dianthicola & A5566 & PRI 1363 & The Netherlands & S. tuberosum & dnaA F1/R1 & MK208962 & $17.44 \pm 0.12$ & $17.44 \pm 0.13$ \\
\hline D. dianthicola & A5567 & PRI 1370 & The Netherlands & S. tuberosum & dnaA F1/R1 & MK208963 & $17.77 \pm 0.10$ & $16.83 \pm 0.15$ \\
\hline D. dianthicola & A5568 & PRI 1372-A & The Netherlands & S. tuberosum & dnaA F1/R1 & MK208964 & $16.37 \pm 0.07$ & $16.48 \pm 0.11$ \\
\hline D. dianthicola & A5569 & PRI 1372-B & The Netherlands & S. tuberosum & dnaA F1/R1 & MK208965 & $13.89 \pm 0.04$ & $13.99 \pm 0.06$ \\
\hline D. dianthicola & A5570 & PRI 1600 & The Netherlands & S. tuberosum & dnaA F1/R1 & MK208966 & $23.15 \pm 0.06$ & $23.09 \pm 0.13$ \\
\hline D. dianthicola & A5572 & PRI 1741-B & The Netherlands & S. tuberosum & dnaA F1/R1 & MK208946 & $17.80 \pm 0.13$ & $17.92 \pm 0.18$ \\
\hline D. dianthicola & A5573 & PRI 2114 & United Kingdom & $\begin{array}{l}\text { D. } \\
\text { caryophyllus }\end{array}$ & dnaA F1/R1 & MK208947 & $13.76 \pm 0.06$ & $13.93 \pm 0.06$ \\
\hline D. dianthicola & A5644 & CFBP2015 & France & S. tuberosum & dnaA F1/R1 & MK208951 & $16.56 \pm 0.07$ & $16.54 \pm 0.07$ \\
\hline D. dianthicola & A5645 & CFBP 4155 & The Netherlands & $\begin{array}{l}\text { Kalanchoe } \\
\text { blossfeldiana } \\
\text { cv. Maes }\end{array}$ & dnaA F1/R1 & MK208952 & $17.10 \pm 0.04$ & $17.31 \pm 0.06$ \\
\hline D. dianthicola & A6058 & CFBP1982 & France & Dahlia & dnaA F1/R1 & MK208953 & $17.73 \pm 0.04$ & $17.17 \pm 0.07$ \\
\hline D. dianthicola & A6059 & CFBP3706 & Switzerland & $\begin{array}{l}\text { Cichorium } \\
\text { intybus }\end{array}$ & dnaA F1/R1 & MK208955 & $18.06 \pm 0.13$ & $17.57 \pm 0.09$ \\
\hline D. paradisiaca & A5420 & CFBP4178 & Colombia & $\begin{array}{l}\text { Musa } \\
\text { paradisiaca }\end{array}$ & dnaA F2/R1 & MK208942 & - & $16.57 \pm 0.07$ \\
\hline D. paradisiaca & A5579 & PRI2127 & Colombia & $\begin{array}{l}\text { M. } \\
\text { paradisiaca }\end{array}$ & dnaA F2/R1 & MK208943 & - & $15.73 \pm 0.06$ \\
\hline $\begin{array}{l}\text { Exclusivity Panel } \\
\text { Pectobacterium } \\
\text { carotovorum ssp. } \\
\text { carotovorum }\end{array}$ & A5278 & $1-\# 21$ & Hawaii, USA & $\begin{array}{l}\text { Irrigation } \\
\text { water }\end{array}$ & Pecto.dnaA & MH453511 & - & - \\
\hline $\begin{array}{l}\text { P. carotovorum ssp. } \\
\text { carotovorum }\end{array}$ & A5280 & $1-\# 31$ & Hawaii, USA & $\begin{array}{l}\text { Irrigation } \\
\text { water }\end{array}$ & Pecto.dnaA & MH453512 & - & - \\
\hline $\begin{array}{l}\text { P. carotovorum ssp. } \\
\text { carotovorum }\end{array}$ & A5368 & $5 X$ & Hawaii, USA & Aglaonema sp. & Pecto.dnaA & MH453510 & - & - \\
\hline $\begin{array}{l}\text { P. carotovorum } s p . \\
\text { carotovorum }\end{array}$ & A5371 & $\mathrm{CC} 26$ & Hawaii, USA & Aglaonema sp. & Pecto.dnaA & MH453528 & - & - \\
\hline $\begin{array}{l}\text { P. carotovorum ssp. } \\
\text { odoriferum }\end{array}$ & A1089 & ATCC15359 & California, USA & Pepper & Pecto.dnaA & MH453518 & - & - \\
\hline $\begin{array}{l}\text { P. carotovorum ssp. } \\
\text { odoriferum }\end{array}$ & A2686 & E43 & Hawaii & $\begin{array}{l}\text { Brassica } \\
\text { oleraceae var. } \\
\text { capitata }\end{array}$ & Pecto.dnaA & MH453519 & - & - \\
\hline $\begin{array}{l}\text { P. carotovorum ssp. } \\
\text { brasiliensis }\end{array}$ & A6149 & WPP5 & Wisconsin, USA & S. tuberosum & Pecto.dnaA & MH453522 & - & - \\
\hline $\begin{array}{l}\text { P. carotovorum ssp. } \\
\text { brasiliensis }\end{array}$ & A6152 & WPP165 & Wisconsin, USA & S. tuberosum & Pecto.dnaA & MH453521 & - & - \\
\hline P. atrosepticum & A1850 & IPM 1260 & Colorado, USA & S. tuberosum & Pecto.dnaA & MH453513 & - & - \\
\hline
\end{tabular}




\begin{tabular}{|c|c|c|c|c|c|c|c|c|}
\hline P. atrosepticum ${ }^{a}$ & A6163 & Eca31 & Wisconsin, USA & S. tuberosum & $16 \mathrm{~S}$ rRNA & - & - & - \\
\hline P. parmentieri & A1852 & M784 & Colorado, USA & S. tuberosum & & MH453534 & - & - \\
\hline P. betavasculorum & A6166 & Ecb2 & California, USA & Beta vulgaris & Pecto.dnaA & MH453532 & - & - \\
\hline P. betavasculorum & A6165 & Ecb1 & California, USA & B. vulgaris & Pec dnaA & MK250993 & - & - \\
\hline $\begin{array}{l}P \text {. carotovorum ssp. } \\
\text { carotovorum }\end{array}$ & A4682 & $9 \mathrm{X}$ & Hawaii, USA & Aglaonema sp. & Pec_dnaA & MK208939 & - & - \\
\hline Erwinia amylovora & A1084 & QR-6 & California & Pyrus sp. & 16S rRNA & MK182851 & - & - \\
\hline P. aroidearum & A5348 & $2 \mathrm{~d}$ & Hawaii, USA & Aglaonema sp. & 16S rRNA & MK182847 & - & - \\
\hline $\begin{array}{l}\text { P. carotovorum ssp. } \\
\text { carotovorum }\end{array}$ & A5350 & $5 \mathrm{C}$ & Hawaii, USA & Aglaonema sp. & Pec_dnaA & MK208940 & - & - \\
\hline Pantoea spp. & A5358 & J9 & Hawaii, USA & $\begin{array}{l}\text { Carica } \\
\text { papaya }\end{array}$ & 16S rRNA & MK182848 & - & - \\
\hline Pantoea spp. & A1865 & YP-1 purple & Hawaii, USA & & $16 \mathrm{~S}$ rRNA & MK182843 & - & - \\
\hline Pantoea spp. & A1867 & $\begin{array}{l}\text { F2 c. } \\
\text { papaya- } \\
\text { purple }\end{array}$ & Hawaii, USA & C. papaya & 16S rRNA & MK182844 & - & - \\
\hline Pantoea spp. & A1869 & F7 c. papaya & Hawaii, USA & & 16S rRNA & MK182845 & - & - \\
\hline $\begin{array}{l}\text { Enterobacter } \\
\text { cloacae }\end{array}$ & A5149 & B193 & Hawaii, USA & $\begin{array}{l}\text { Zingiber } \\
\text { officinale }\end{array}$ & 16S rRNA & MK182850 & - & - \\
\hline E. asburiae & A5150 & - & Hawaii, USA & Z. officinale & 16S rRNA & MK182852 & & \\
\hline $\begin{array}{l}\text { Klebsiella } \\
\text { aerogenes }\end{array}$ & A3131 & ATCC13048 & - & - & Pecto.dnaA & MK208954 & - & - \\
\hline $\begin{array}{l}\text { Pantoea } \\
\text { agglomerans }\end{array}$ & A5513 & & Hawaii, USA & Ornamental & $16 \mathrm{~S}$ rRNA & MK182849 & - & - \\
\hline P. cypripedii & A5186 & ATCC29267 & California, USA & $\begin{array}{l}\text { Cypripidium } \\
\text { sp. }\end{array}$ & 16S rRNA & MK182846 & - & - \\
\hline $\begin{array}{l}\text { C. michiganensis } \\
\text { subsp. nebraskensis }\end{array}$ & A6205 & DP115A & Iowa, USA & Zea mays & 16S rRNA & MH560463 & - & - \\
\hline $\begin{array}{l}\text { C. michiganensis } \\
\text { subsp. sepedonicus }\end{array}$ & A2041 & $\mathrm{R} 8$ & Denmark & S. tuberosum & $\mathrm{CM}$ dnaA & MK560493 & - & - \\
\hline $\begin{array}{l}\text { C. michiganensis } \\
\text { subsp. sepedonicus }\end{array}$ & A6172 & $\begin{array}{l}\text { ATCC } \\
33113\end{array}$ & Canada & S. tuberosum & $\mathrm{CM}$ dnaA & MK560494 & - & - \\
\hline $\begin{array}{l}\text { Pantoea } \\
\text { agglomerans }\end{array}$ & A6215 & DP105A & Iowa, USA & Z. mays & 16S rRNA & MH547380 & - & - \\
\hline Pantoea ananatis & A6219 & DP132A & Kansas, USA & Z. mays & 16S rRNA & MH547385 & - & - \\
\hline $\begin{array}{l}\text { Pantoea } \\
\text { agglomerans }\end{array}$ & A6222 & DP138 & Wisconsin, USA & Z. mays & $16 \mathrm{~S}$ rRNA & MH547382 & - & - \\
\hline $\begin{array}{l}\text { Klebsiella spp. } \\
\text { Agrobacterium }\end{array}$ & A2961 & C58 & New York, USA & Prunus avium & 16S rRNA & MK182842 & - & - \\
\hline Soil & & & & & & & - & - \\
\hline Healthy potato & & & & & & & - & - \\
\hline
\end{tabular}

Healthy potato plants were grown in a greenhouse. Before planting, the sprouting seed potatoes were cut into two pieces, and a piece having at least two buds was planted into a separate pot and placed on the greenhouse bench. Four-week-old healthy potato plants were inoculated with $D$. dianthicola strains. For plant inoculations, sterile scalpels were used to make wounds at the base of the stems of the healthy plants and a loopful of bacteria was stabbed into the fresh wound. The inoculated plants were covered individually with the plastic bags to maintain the humidity, tied and incubated at 28 to $30^{\circ} \mathrm{C}$ for $24-48 \mathrm{~h}$. Black leg symptoms were observed at the base of the stem three days after inoculation. Healthy plants inoculated with sterile water showed no symptoms. The DNA was extracted from the healthy and inoculated plants.

\section{Genomic DNA extraction, identification and phylogenetic analysis}

Extraction of genomic DNA from infected and healthy plant materials was performed using the Wizard Genomic DNA purification kit (Promega, Madison, WI); DNA was isolated from bacterial cultures using the Ultra Clean Microbial DNA Isolation kit (Mo Bio., Carlsbad, CA). For microbial 
DNA isolation, 3-4 loopfuls of bacterial cultures from plates were suspended in $300 \mu$ of the microbead solution and vortexed gently to mix; Mini-BeadBeater 16 (Biospec products, Bartlesville, OK) was used to rupture the cell wall at maximum speed for $1 \mathrm{~min}$; bacterial DNA was isolated following the manufacturer's instructions. DNA concentration and purity were measured using NanoDrop 2000/c spectrophotometers (Thermo Fisher Scientific Inc., Worcester, MA). The genomes of all Dickeya, and Pectobacterium species were aligned separately with progressive Mauve (Darling et al, 2010); Geneious (version 10.1.3) was used to evaluate the aligned genomes for the dnaA (replication initiation factor) regions (data not shown). The primers were designed using Primer3 online software (Rozen, S. \& Skaletsky, 2000) following the parameters described by Arif and Ochoa-Corona (2013). The P16s-F1 (5'AGACTCCTACGGGAGGCAGCA-3') and P16s-R1 (5'-TTGACGTCATCCCCACCTTCC-3') were used for $16 \mathrm{~S}$ region amplification (Dobhal et al. 2018). The primer set Dic.dnaA-F1 (5'TAACAACGTGAACCCCAACGA-3') and Dic.dnaA-R1 (5'TCTTCTTTGATGTCGTGACTTTC-3') targeting dnaA region of Dickeya was used to amplify all Dickeya species except D. paradisiaca where Dic.dnaA-F2 (5'TCCAATGTGAATCCCAAACA-3') was used in combination with Dic.dnaA-R1. Pectobacterium Pec.dnaA-F1 (5'-CATACGTTTGATAACTTCGTTG-3') and Pec.dnaA-R1 (5'GATGTCGTGGCTTTCTTCAC-3') primers were used to amplify the dnaA gene region of Pectobacterium species. The identity of other bacteria listed in the exclusivity panel was confirmed using primers P16s-F1 and P16s-R1 targeting the $16 \mathrm{~S}$ ribosomal RNA region. The PCR conditions used for Dickeya and Pectobacterium dnaA gene amplifications were: Initial denaturation at $95^{\circ} \mathrm{C}$ for $5 \mathrm{~min}$ followed by 35 cycles with $95^{\circ} \mathrm{C}$ for $20 \mathrm{~s}, 58^{\circ} \mathrm{C}$ for $1 \mathrm{~min}, 72^{\circ} \mathrm{C}$ for $1 \mathrm{~min}$ and a final extension at $72^{\circ} \mathrm{C}$ for $3 \mathrm{~min}$. The amplified PCR products were cleaned by adding $2 \mu \mathrm{l}$ ExoSAPIT (Affymetrix Inc, Santa Clara, CA) in $5 \mu 1$ of PCR product and incubated at $37^{\circ} \mathrm{C}$ for $15 \mathrm{~min}$ followed by enzyme inactivation at $80^{\circ} \mathrm{C}$ for $15 \mathrm{~min}$. Sequencing was performed at the GENEWIZ facility (Genewiz, La Jolla, CA) for both sense and anti-sense strands. Obtained sense and antisense strands of each strain were aligned, manually edited and the error free consensus sequence was used to confirm identity by comparing the sequences of each strain against the NCBI GenBank nucleotide and genome databases using NCBI BLASTn tool. Sequences generated from each strain were deposited in the NCBI GenBank database and the accessions numbers are listed in Table 1. Consensus sequences of 46 strains used in this study were aligned to generate a phylogenetic tree. Phylogenetic relationships among the strains was generated using the Neighbor-Joining method and the evolutionary distances were calculated using Tamura-Nei method; evolutionary analyses were constructed in MEGA-X (MEGA X; Centre for Evolutionary Functional Genomics) (Saitou and Nei 1987; Felsenstein 1985; Tamura and Nei 1993; Kumar et al. 2018). Gaps or undetermined data in the alignment were excluded when site coverage was below 95\%. Bootstrap percentages were calculated with 1,000 replicates. The color-coded matrix showing pairwise similarity was generated using Sequence Demarcation Tool v1.2 (Mulshire et al. 2014) with the default parameters.

\section{Target gene selection, genus- and species-specific TaqMan primers and probe design}

Genomes of D. chrysanthemi strain NCPPB516 (NZ_CM001904), D. dadantii strain 3937 (CP002038/NC_014500), D. dianthicola strain GBBC 2039 (NZ_CM001838), NCPPB3534 (NZ_CM001840), NCPPB 453 (NZ_CM001841), strain IPO 980 (NZ_CM002023), D. fangzhongdai strain DSM 101947 (NZ_CP025003), D. paradisiaca strain Ech 703 (CP001654), D. solani strain IPO 2222 (NZ_CP015137), strain ND14b (NZ_CP009460), D. zeae strain EC1 
(NZ_CP006929), strain Ech586 (NC_013592), Pectobacterium carotovorum subspecies carotovorum strain PCC21 (NZ_018525), P. atrosepticum strain 21A (NZ_CP009125), $P$. wasabiae strain CFBP 3304 (NZ_CP015750), Erwinia amylovora strain CFBP1430 (NC_013961), Ralstonia solanacearum GMI 1000 (NC_003295), and Clavibacter sepedonicus strain ATCC33113 (NC_10407) were retrieved from NCBI GenBank Genome database (Supplementary Table 1). Whole genomes were aligned using progressive Mauve (2.4.0) and Geneious (10.2.3). Generated locally Collinear Blocks (LCBs) were analyzed to search unique and conserved regions for the genus Dickeya and D. dianthicola. The galactose/methyl galactoside $\mathrm{ABC}$ transporter ATP-binding protein $\mathrm{MglA} / \mathrm{MglC}$ region was used to design the primers and probe specific for the genus Dickeya. Similarly, for $D$. dianthicola, the genomes of $D$. dianthicola (NZ_CM001838, NZ_CM001840, NZ_CM001841 and NZ_CM002023) were retrieved from the NCBI GenBank Genome database (Supplementary Table 1) and aligned using progressive Mauve; Geneious was used for analyzing the unique genes present in the D. dianthicola genome. The alcohol dehydrogenase gene was used to design the primers and probe specific for $D$. dianthicola. The representative genome of each Dickeya species and all available complete genomes of $D$. dianthicola along with the genomes of other closely related genera and selected target gene locations were included to generate a BLAST Ring Image Generator (BRIG) 40 (Figure 1) (Alikhan et al. 2011). NCBI-BLAST 2.6.0+ database was used to compare and generate the BRIG image. The genus and species-specific primers and fluorescence-labelled probes for the multiplex qPCR assay were designed using Primer3 software and evaluated for thermodynamic characteristics following the parameters described by Arif and Ochoa-Corona (2013). Customized flap sequences were added at 5' end of each primer designed for genus Dickeya and D. dianthicola to adjusted Tm, GC content and the length of the primers as previously described (Arif and OchoaCorona 2013; Larrea et al. 2019). The primers with and without flap sequences along with the thermodynamic parameters are presented in Table 2. No flap sequences were added to the probes. The specificity of each primer was confirmed in silico using the BLASTn tool against the NCBI GenBank nucleotide and genome databases (Table 2). All primers and double-quencher probes 5'/6FAM/ZEN/3IBQ/-3' and 5'-/5HEX/ZEN/3IBQ/-3' were synthesized by IDT (Integrated DNA Technologies, Inc., Coralville, IA).

Table 2: Details of primers and probes used to develop Multiplex TaqMan real-time qPCR assay for specific and rapid detection of all known Dickeya species and D. dianthicola.

\begin{tabular}{|c|c|c|c|c|c|c|c|c|c|}
\hline \multirow{2}{*}{$\begin{array}{l}\text { Primer } \\
\text { name }\end{array}$} & \multirow[t]{2}{*}{ Sequence 5'-3' } & \multirow{2}{*}{$\begin{array}{l}\text { Fluorochro } \\
\text { me/channel } \\
\text { used in } \\
\text { Rotor Gene }\end{array}$} & \multirow{2}{*}{$\begin{array}{l}\text { Quench } \\
\text { er }\end{array}$} & \multirow{2}{*}{$\begin{array}{l}\text { Length } \\
\text { (bp) }\end{array}$} & \multirow{2}{*}{$\begin{array}{l}\mathrm{Tm} \\
\left({ }^{\circ} \mathrm{C}\right)\end{array}$} & \multirow[t]{2}{*}{$\% G C$} & \multicolumn{3}{|c|}{ BLASTn Results* } \\
\hline & & & & & & & $\begin{array}{l}\text { Query } \\
\text { Cover (\%) }\end{array}$ & $\begin{array}{c}\mathrm{E} \\
\text { value }\end{array}$ & $\begin{array}{c}\% \\
\text { identity }\end{array}$ \\
\hline DICg-F1 & GCATTGTCGAAACCAAGAACAC & & & 22 & 53 & 45 & 100 & 0.019 & 100 \\
\hline DICg-R1 & TGTCTTTCAGCCAGGTGAGC & & & 20 & 54 & 55 & 100 & 0.30 & 100 \\
\hline DICg-P & $\begin{array}{l}\text { ATGATGCAAGGGCTGTTACCATGAA } \\
\text { AGC }\end{array}$ & HEX/yellow & BHQ1 & 28 & 60 & 46 & 100 & $2 \mathrm{e}-05$ & 100 \\
\hline DICg-F1 wf & $\begin{array}{l}\text { ATTATCTCTGCATTGTCGAAACCA } \\
\text { AGAACAC }\end{array}$ & & & 31 & 59 & 39 & - & - & - \\
\hline DICg-R1 wf & $\begin{array}{l}\text { AAATTATTTCTTGTCTTTCAGCCAG } \\
\text { GTGAGC }\end{array}$ & & & 31 & 59 & 39 & - & - & - \\
\hline Ddia-F1 & GTGAGCTTGGCATCAAGGAA & & & 20 & 52 & 50 & 100 & 0.30 & 100 \\
\hline
\end{tabular}


bioRxiv preprint doi: https://doi.org/10.1101/847590; this version posted November 20, 2019. The copyright holder for this preprint (which was not certified by peer review) is the author/funder, who has granted bioRxiv a license to display the preprint in perpetuity. It is made available under aCC-BY-NC-ND 4.0 International license.

\begin{tabular}{|c|c|c|c|c|c|c|c|c|c|}
\hline Ddia-R1 & CGTCGTCCAACAAAATGCAG & & & 20 & 52 & 50 & 100 & 0.30 & 100 \\
\hline Ddia-P & CAAGGCCGAACTGCTGGCGATGTAT & FAM/Green & BHQ1 & 25 & 61 & 56 & 100 & $8 \mathrm{e}-04$ & 100 \\
\hline Ddia-F1 wf & $\begin{array}{l}\text { TCTACTATTTTGTGAGCTTGGCATC } \\
\text { AAGGAA }\end{array}$ & & & 31 & 59 & 39 & - & - & - \\
\hline Ddia-R1 wf & $\begin{array}{l}\text { TTATAACATTCCGTCGTCCAACAA } \\
\text { AATGCAG }\end{array}$ & & & 31 & 59 & 39 & - & - & - \\
\hline
\end{tabular}

*Results of the analysis on 5/22/18. The Tm length and \% GC content were calculated using MBCF Oligo calculator (http://mbcf149.dfci.harvard.edu/docs/oligocalc.html). The primers in bold are the flap sequences added to the 5' position of the forward and reverse primers.

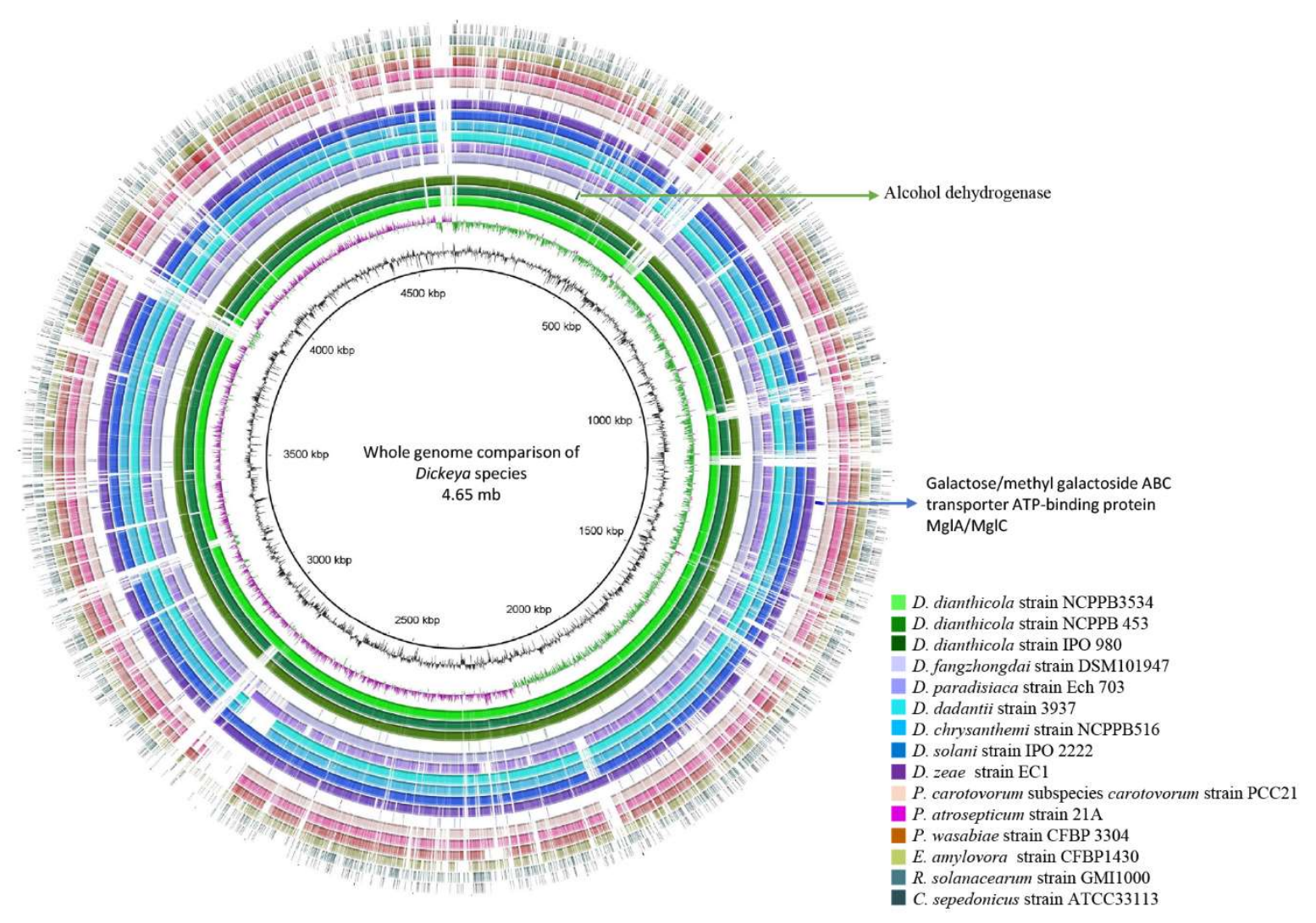

Figure 1. Location of genes used for specific primer and probe design within the whole genome BLAST ring comparison of Dickeya species and the closely related bacteria sharing a similar niche with the pathogen. The complete genome of D. dianthicola GBBC 2039/LMG25864 (NZ_CM001838) was used as a reference. The GC content and the GC skew (+,-) of the reference genome are represented with the black, purple and green rings. Rings from inside to outside represent the BLAST ring comparison of the whole genomes of D. dianthicola strain NCPPB3534 (NZ_CM001840), NCPPB 453 (NZ_CM001841), strain IPO 980 (NZ_CM002023); D. fangzhongdai strain DSM 101947 (NZ_CP025003), D. paradisiaca strain Ech 703 (NZ_CM001857), D. dadantii strain 3937 (CP002038/NC_014500), D. chrysanthemi strain NCPPB516 (NZ_CM001904), D. solani strain IPO 2222 (NZ__CP015137), D. zeae strain EC1 (NZ_CP006929), Pectobacterium carotovorum subspecies carotovorum strain PCC21 (NZ_018525), Pectobacterium atrosepticum strain 21A (NZ_CP009125), Pectobacterium 
wasabiae strain CFBP 3304 (NZ_CP015750), Erwinia amylovora strain CFBP1430 (NC_013961), Ralstonia solanacearum GMI 1000 (NC_003295), and Clavibacter sepedonicus strain ATCC33113 (NC_10407). The blue and green arrows indicate the location of the region for the galactose/methyl galactoside ABC transporter ATP-binding protein MgIA/MglC and alcohol dehydrogenase, respectively. The BLAST RING IMAGE GENERATOR (BRIG) 40 (Alikhan et al., 2011) was used to generate the image. Plasmids were not included in the analysis.

\section{Multiplex TaqMan real-time qPCR assay}

The multiplex TaqMan qPCR was performed in Rotor-Gene Q (Qiagen, Germatown, MD). The concentrations of the primers and probes were adjusted to obtain the optimal amplification. The primer mix was prepared by adding $10 \mu \mathrm{l}$ of each forward and reverse primer (from stock: 100 $\mu \mathrm{mol} \mathrm{1}^{-1}$ ) for genus Dickeya and $D$. dianthicola and $160 \mu 1$ nuclease free water. The multiplex TaqMan reactions were initially performed in two combinations: primers without 5' AT-rich flap sequences and with 5' AT-rich flap sequences. The multiplex TaqMan qPCR reaction was carried out in $25 \mu \mathrm{l}$ reaction mixture containing $12.5 \mu \mathrm{l}$ of Rotor-Gene Multiplex PCR Master Mix (Qiagen), $2 \mu \mathrm{l}$ of the primer mix ( $5 \mu \mathrm{mol} \mathrm{l}^{-1}$ each), $0.5 \mu 1$ of each DICg-P and Ddia-P probes (5 $\mu \mathrm{mol} \mathrm{l}^{-1}$ stock), $1 \mu \mathrm{l}$ of template DNA and nuclease free water was adjusted to obtain final volume. Positive and negative controls (non-template; water) were included in each TaqMan qPCR amplification run. Each qPCR reaction was performed in three replicates; standard deviation was calculated. Temperature cycling conditions were: $5 \mathrm{~min}$ at $95^{\circ} \mathrm{C}$, followed by 40 cycles of $95^{\circ} \mathrm{C}$ for $30 \mathrm{~s}$, and $60{ }^{\circ} \mathrm{C}$ for $15 \mathrm{~s}$, acquiring fluorescence on both green (FAM) and yellow (HEX) channels at the end of each extension step. The data analysis was done using the Rotor-Gene Q series software 2.3.1 (Built 49) with auto threshold (Ct); dynamic tube-based normalization was used.

\section{Exclusivity and inclusivity panels for specificity validation}

The specificity of the developed multiplex TaqMan qPCR was validated using the individual DNA template from all 67 bacterial strains included in the inclusivity and exclusivity panels (Table 1). The specificity assays were performed using the primers with flap sequences. All reactions were performed in triplicate; positive and negative template controls were included in each qPCR run. The data analysis was done as described above.

\section{Multiplex TaqMan qPCR limit of detection determination with and without 5' AT-rich flap sequences and host background}

To minimize the variations among the assays, all sensitivity experiments were performed using the same serial dilutions on the same day. The sensitivity was performed using a ten-fold serially diluted purified genomic DNA (10 ng to $1 \mathrm{fg}$ ) of $D$. dianthicola (A5569). To compare the sensitivity, two sets of assays were performed, one using the primer mix with no flap and other using the primer mix with flap primers. The limit of detection of the developed assay was determined in a host DNA background: $1 \mu \mathrm{l}$ of host (potato) genomic DNA (10 ng $\left.\mu \mathrm{l}^{-1}\right)$ was added in each 10-fold serially diluted genomic DNA of D. dianthicola (A5569) from $10 \mathrm{ng}$ to $1 \mathrm{fg}$. The assays were performed in triplicate. These dilutions along with a no-template control (NTC, water) were run in a Rotor-Gene Q Thermocycler; the TaqMan real-time qPCR conditions were used as 
described above. The estimated genome size of $D$. dianthicola is $\sim 4.86 \mathrm{Mb}$. Based on the genome size, the copy number was calculated using the formula: number of copies (molecules) $=$ $\frac{\mathrm{Xng} * 6.0221 \times 10^{23} \mathrm{molecules} / \mathrm{mole}}{(\mathrm{N} * 660 \mathrm{~g} / \mathrm{mole}) * 1 * 10^{9} \mathrm{ng} / \mathrm{g}}$ (where $\mathrm{X}=$ amount of amplicon $(\mathrm{ng}), \mathrm{N}=$ length of dsDNA amplicon, $660 \mathrm{~g} / \mathrm{mole}=$ average mass of $1 \mathrm{bp}$ dsDNA) or web based software (www.scienceprimer.com/copy-number-calculator-for-realtime-pcr).

Comparison of the sensitivity of the Multiplex TaqMan qPCR with single TaqMan qPCR

To compare the sensitivity of the multiplex with the single TaqMan qPCR assay, the ten-fold serially diluted DNA was used with the single flap primer set. Two separate reaction mixes were prepared, one containing the primer set targeting the genus Dickeya and the other targeting $D$. dianthicola. The ten-fold serial dilution sensitivity was performed in the similar way as described above.

\section{Validation of TaqMan real-time qPCR with naturally infected symptomatic potato samples}

The capability of the developed assay was tested with naturally infected potato samples collected from the field. A total of twenty-four plant samples were brought to the lab and washed with sterile water; stem explant of $1 \mathrm{~cm}$ size was taken in an Eppendorf tube and crushed with small pestle; DNA was isolated using the Wizard Genomic DNA purification kit. The DNA was quantified using Nanodrop and used for the multiplex TaqMan real-time qPCR. The multiplex TaqMan qPCR was performed using the reaction components and conditions as described above. Three replicates of each sample were run along with the positive and the negative controls.

\section{Screening of infected plant samples and water sources}

The developed TaqMan qPCR was used to screen the samples, collected from six potato growing states of USA, for the genus Dickeya and/or D. dianthicola contamination/infection. A total of 132 asymptomatic, symptomatic plant samples which included potato stems, tubers and roots, and 3 from potato fields water sources, were screened. The tests were performed at the Wisconsin Seed Potato Certification Laboratory (Wisconsin, USA). Each sample was replicated once; the positive and the negative template controls (NTC) were included in each test run.

\section{Results}

\section{Genome comparison, primer design and in-silico analysis}

The highly conserved region present only in the core genome of $D$. dianthicola as well as the genus Dickeya was found by evaluating sixteen genomes of the genera Dickeya,Pectobacerium, Erwinia, Ralstonia and Clavibacter using BLAST comparisons and MAUVE (Figure 1). Mauve-based progressive whole genome alignments enabled the gene selection for the Dickeya species and $D$. dianthicola. The alcohol dehydrogenase gene region was identified as a signature gene region present in the core genome of $D$. dianthicola and was used for designing the robust primers and probe specifically amplifying this species. Furthermore, the galactose/methyl galactoside ABC transporter ATP-binding protein $\mathrm{mglA} / \mathrm{mglC}$ region was identified as a unique target for designing the primers and probe amplifying all known species of genus Dickeya (Figure 1). This gene is a part of $\mathrm{ABC}$ transporter complex and involved in the import of galactose/methyl galactoside by ATP hydrolysis. Both sets of designed primers and probes were analyzed by BLAST against the NCBI GenBank database and showed 100\% query coverage and 100\% similarity only corresponding to their target species that is Dickeya and D. dianthicola (Table 2). 


\section{Identity confirmation and phylogenetic analysis}

To determine identities and relationships, all bacterial strains present in inclusivity and exclusivity panels were sequenced. Pectobacterium and Enterobacter strains were amplified and sequenced using either dnaA or $16 \mathrm{~S}$ rRNA specific primer set to confirm their identity (Table 1). A manually corrected and proofread dnaA consensus sequence of $\sim 742$ bp was generated. Consensus sequences, produced from both strands, were queried against the NCBI GenBank database using the BLASTn tool to confirm the identity of each strain mentioned in Table 1. The phylogenetic relationships among the bacterial strains were determined using MEGA-X and the sequence demarcation tool (v1.2), clearly grouped the strains of Dickeya species from the Pectobacterium. All Dickeya species strains were clustered together except D. paradisiaca which was out-grouped (Figure 2 and 3). The strains of Pectobacterium species were clustered all together.

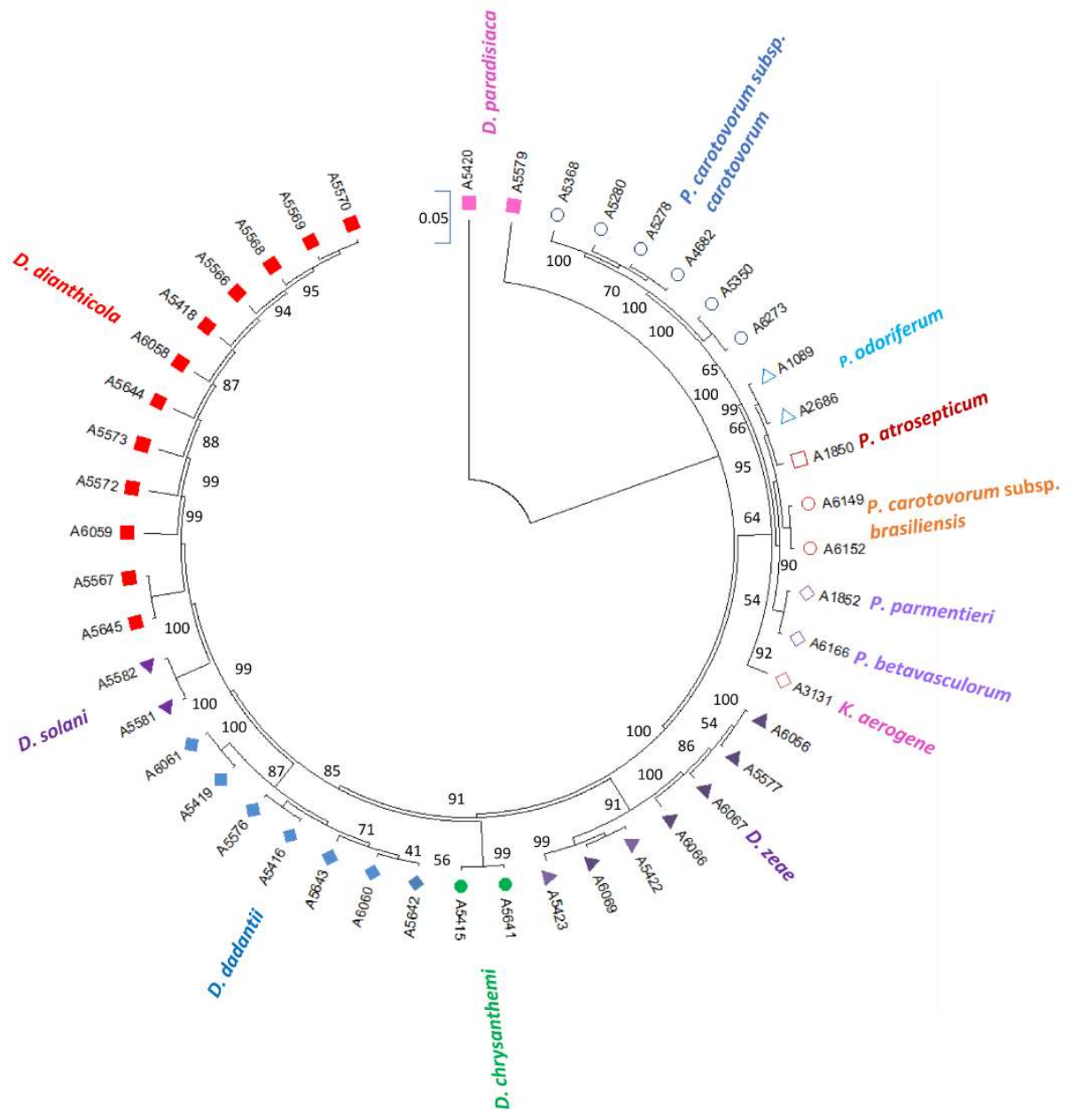

Figure 2. Phylogenetic analyses of Dickeya strains using dnaA gene conducted in MEGA X. The analysis was inferred using the Neighbor-Joining method. The optimal tree with the sum of branch length $=0.91379220$ is shown. The percentage of replicate trees in which the associated taxa clustered together in the bootstrap test (1000 replicates) are shown next to the branches. The evolutionary distances were computed using the Tamura-Nei method and are in the units of the number of base substitutions per site. Evolutionary analyses were conducted in MEGA X. The analysis involved 46 nucleotide sequences which includes Dickeya, Pectobacterium and 
Enterobacter species. All Dickeya strains grouped together except two D. paradisiaca strains that form a separate clade. All Pectobacterium species clustered together.

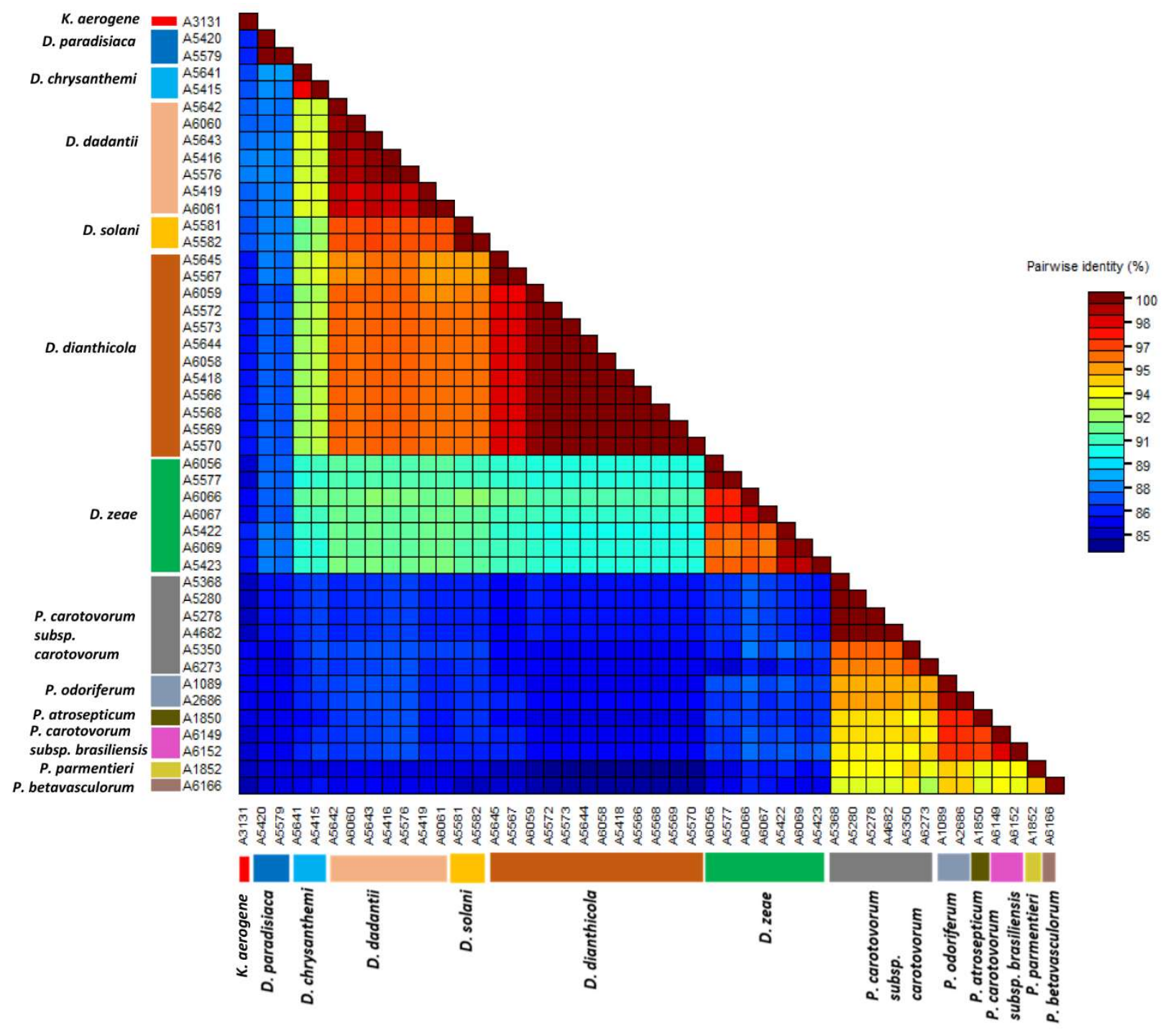

Figure 3. Color-coded matrix showing pairwise identity scores between $d$ naA gene sequences of strains of Dickeya sp. with strains of other Pectobacterium sp. and Enterobacter aerogenes. species. Forty-six partial sequences were used for constructing the pairwise similarity scores displaying a color-coded matrix considering the number of mismatching and the number of positions along the alignment.

\section{Specificity of the TaqMan primers and probes}

The in-silico analyses were performed via similarity search of each primer sequence against the NCBI GenBank database using the BLASTn tool; primers showed $100 \%$ specificity with query coverage and percent identity match of $100 \%$ with the target Dickeya genus and the species 
dianthicola (Table 2). During in-vitro experiments, the specificity of the developed assay was tested with the DNA from 13 and 20 strains of D. dianthicola and other species of Dickeya from distinct geographical origins, respectively (Table 1). The Ct values from Dickeya strains, excluding $D$. dianthicola, ranged from $13.89 \pm 0.04$ to $30.84 \pm 0.11$ in the yellow channel $(n=18)$, while the green channel showed amplification and $\mathrm{Ct}$ values from $13.76 \pm 0.06$ to $23.15 \pm 0.06$ with the strains of $D$. dianthicola $(\mathrm{n}=13)$. The yellow channel exhibited almost similar $\mathrm{Ct}$ values as the green channel for the same strains of $D$. dianthicola (13.93 \pm 0.06 to $23.09 \pm 0.13$ ). No amplification in green or yellow channels were observed from the non-target and/or closely related species $(\mathrm{n}=34)$. This demonstrated that the developed primers/probes are highly specific for the genus Dickeya and specifically for $D$. dianthicola (Table 1). No Ct values were observed in either green or yellow channels with any member of the exclusivity panel, healthy plant or soil sample included in the assay validation. In addition, during the specificity validation, no $\mathrm{Ct}$ value $>35$ was obtained with any member of the inclusivity panel. The amplification from each representative species from genus Dickeya is shown in Figure 4. The primers with and without 5' AT-rich flap sequences were also tested for their specificity; no false positives or false negatives were obtained (data not shown). The assays were highly specific but still the samples with $\mathrm{Ct}$ value after 35 cycles were considered negative.
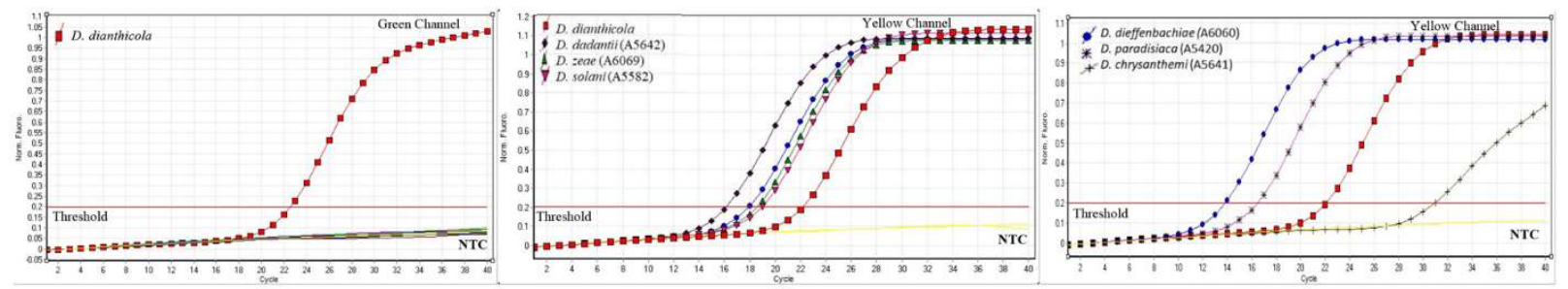

Figure 4. Multiplex TaqMan qPCR assay showing representative strains of Dickeya species included in the inclusivity panel. The green and yellow channels correspond to the different reporter dyes 6-FAM (495/520) and HEX (535/554) (excitation/emission spectra in $\mathrm{nm}$ ) for detection of genus and species of Dickeya, respectively. NTC, Non-template control. Each reaction was performed in triplicate.

\section{Limit of detection determination}

The primer sets with and without flap sequences were compared for their sensitivity using the purified D. dianthicola genomic DNA. Both primer sets with and without flaps were sensitive and detected $10 \mathrm{fg}$ of purified genomic DNA (Figure 5A1, A2; 5B1, B2). The primers with the 5' ATrich flap showed better reaction efficiency compared to the primer set with no flap (Figure 5A1, A2). At lower concentrations of template DNA, the primers with no AT-rich flap sequences showed higher standard deviation among the replicates compared to primers with flap, indicating the enhanced stability and better reaction thermodynamics.

No change in the sensitivity was observed when $1 \mu 1$ of host genomic DNA (DNA extracted from healthy potato plant) was added to each ten-fold serially diluted genomic DNA. The detection limit of $10 \mathrm{fg}$ was detected; demonstrating the robustness of the developed assay with no adverse effect from host background DNA (Figure 5C1, C2). 
To demonstrate the robustness of the multiplex TaqMan qPCR, a single TaqMan qPCR assay was also performed to compare the detection limit using both primer/probe sets. Primer sets DICgF1/R1-wf and Ddia-F1/R1-wf were able to detect up to $10 \mathrm{fg}$ in both yellow and green reporting channels, respectively. These results indicated that the developed multiplex assay is robust and equally sensitive as single target TaqMan real-time qPCR assay (Figure 5D1, D2).
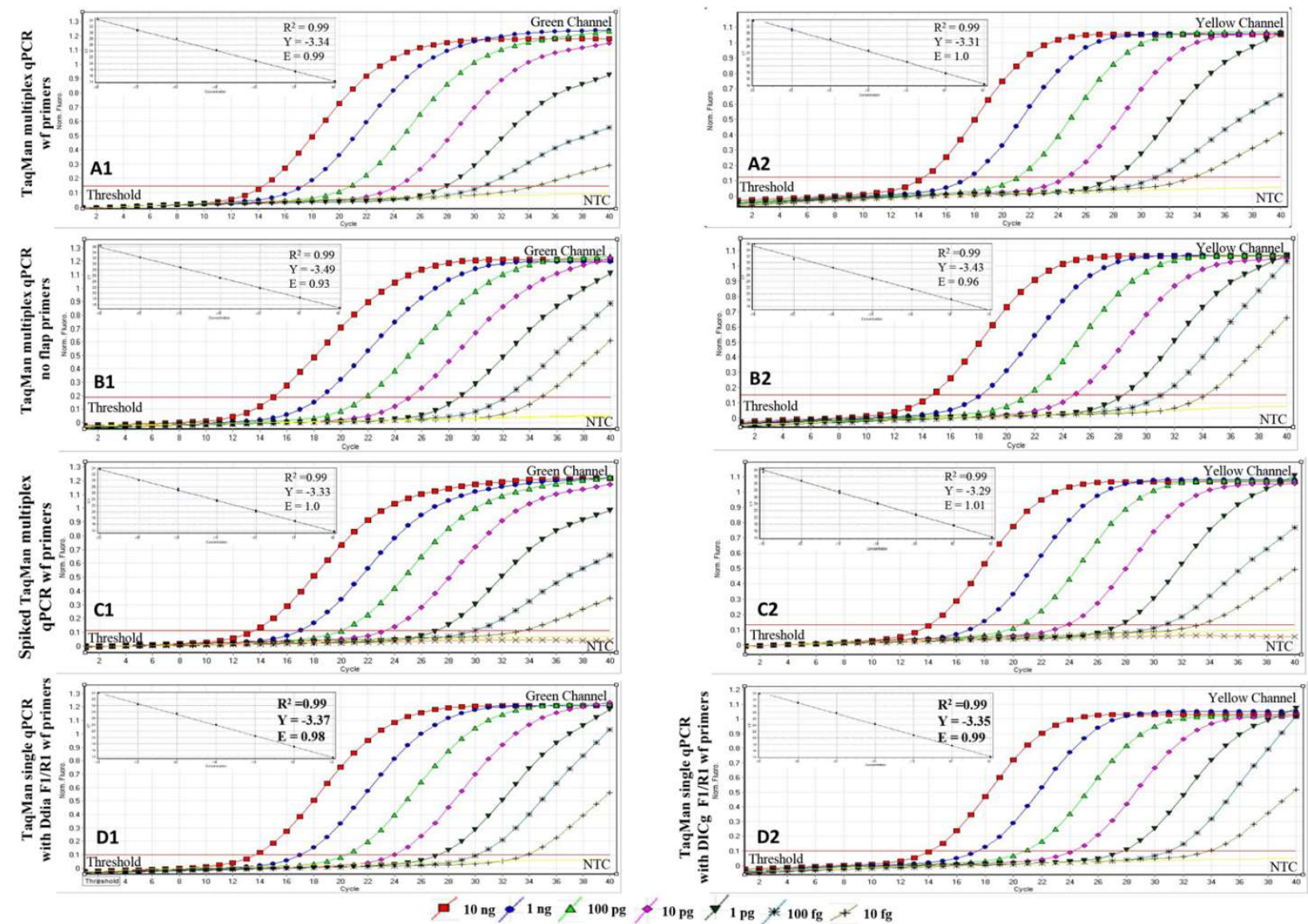

Figure 5. Multiplex and single TaqMan qPCR standard curves and graphs. The graphs and curves were generated using ten-fold serial diluted genomic DNA (10 ng to $1 \mathrm{fg}$ ) of Dickeya dianthicola (A, B, D) and ten-fold serially diluted genomic DNA mixed with host plant DNA (C). The Green and yellow channels correspond to the different reporter dye 6-FAM (495/520) and HEX (535/554) (excitation/emission spectra in $\mathrm{nm}$ ), respectively. A1/A2 multiplex TaqMan qPCR using DICgF1/R1wf and Ddia F1/R1 wf (wf -with flap primers) primer sets in the reaction mix. B1/B2 multiplex TaqMan qPCR using DICg-F1/R1 and Ddia F1/R1 (no flap primers) primer sets in the reaction mix. C1/C2 spiked multiplex TaqMan qPCR using DICg-F1/R1wf and Ddia F1/R1 wf (wf -with flap primers) primer sets in the reaction mix (the spiked assay was done by adding $1 \mu \mathrm{l}$ of healthy plant-potato DNA extracted from tubers to each serial dilution to simulate natural infection and then performing the multiplex qPCR assay). D1 single TaqMan qPCR with Ddia F1/R1 wf primer set in a reaction mix. D2 single TaqMan qPCR with DICg F1/R1 wf primer set in a reaction mix. The $\mathrm{C}_{T}$ values represent the average of three replicates $\pm S D$. Slopes $(\mathrm{Y}=$ threshold cycles $(\mathrm{Ct})$ of target DNA detected), $\mathrm{R}^{2}$ (correlation coefficient), and $\mathrm{E}$ (= amplification efficiency of the real-time PCR assay) of each reaction are presented in the respective curves. X axis represents the number of cycles, and $\mathrm{Y}$ axis is normalized fluorescence. 


\section{Multiplex TaqMan qPCR validation with naturally infected plant samples}

A total of 13 naturally infected asymptomatic and symptomatic plants were tested positive using the developed multiplex TaqMan real-time qPCR; all samples gave positive results using both the Dickeya genus and $D$. dianthicola specific primer sets. The $\mathrm{Ct}$ values in both yellow and green channels ranged from $18.02 \pm 0.04$ to $32.37 \pm 0.52$ and $18.16 \pm 0.01$ to $34.08 \pm 1.07$, respectively. The bacteria were isolated from the positive samples and sequenced with forward and reverse primers described previously to confirm their identity. The multiplex qPCR showed $100 \%$ accuracy in detection of the Dickeya infected field samples. No false positives or false negatives were detected during the experiment (Figure 6).
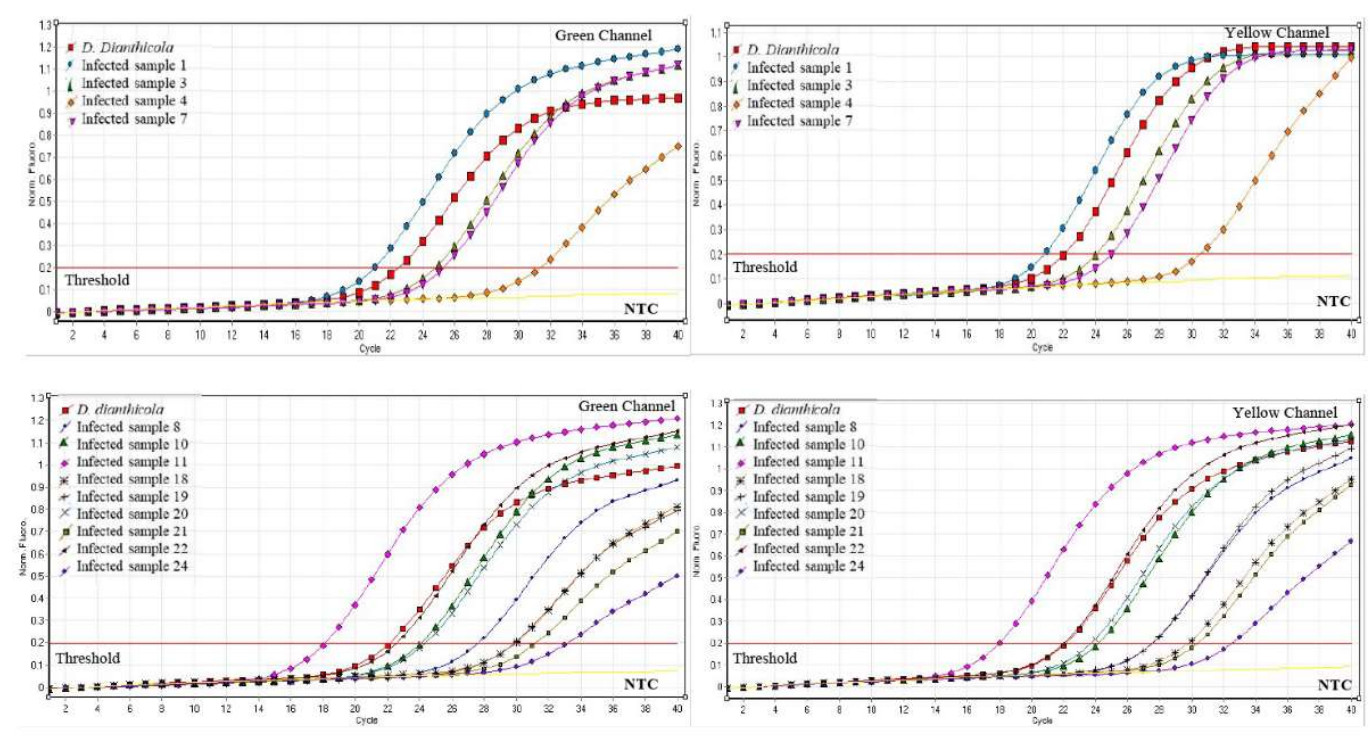

Figure 6. Multiplex TaqMan qPCR assay using infected field samples. The Green and yellow channels correspond to the different reporter dye 6-FAM (495/520) and HEX (535/554) (excitation/emission spectra in $\mathrm{nm}$ ), respectively. D. dianthicola, Positive control; Infected potato plant samples 1, 3, 4, 7, 8, 10, 11, 18, 19, 20, 21, 22 and 24; NTC, Non-template control. Each reaction was performed in three replicates.

\section{Multiplex TaqMan qPCR assay validation with different sample types collected from multiple locations}

The developed multiplex TaqMan real-time qPCR was used to screen 143 field samples (stem, potato tuber, root and water) for Dickeya and specifically for D. dianthicola infection (Table 3). Out of 143 samples, 61 were positive for genus Dickeya and of these, 60 were positive for $D$. dianthicola. Samples crossing the threshold value $(\mathrm{Ct})$ after 35 cycles were considered negative.

Table 3: Samples tested during performance evaluation of the multiplex TaqMan real-time qPCR for specific detection of Dickeya species and $D$. dianthicola from naturally infected potato tissues.

\begin{tabular}{lcc}
\hline Sample Type & Location/State & \multicolumn{2}{c}{ Total number of samples tested positive/total number of } \\
& & samples tested (\%) \\
\hline & DICg-F1/R1 $\mathrm{wf}$ & Ddia-F1/R1 wf \\
(Dickeya genus) & $($ D. dianthicola $)$ \\
\hline
\end{tabular}




\begin{tabular}{llll}
\hline $\begin{array}{l}\text { Plant samples } \\
\text { includes plant } \\
\text { parts) }\end{array}$ & & & \\
\hline Stems & Missouri & $19 / 20(95 \%)$ & $19 / 20(95 \%)$ \\
Stems & North Carolina & $5 / 5(100 \%)$ & $5 / 5(100 \%)$ \\
Stems & Indiana & $3 / 3(100 \%)$ & $3 / 3(100 \%)$ \\
Stems & Florida & $14 / 14(100 \%)$ & $14 / 14(100 \%)$ \\
Stems & Texas & $3 / 3(100 \%)$ & $3 / 3(100 \%)$ \\
Stems & Idaho & $3 / 3(100 \%)$ & $3 / 3(100 \%)$ \\
Stems & Wisconsin & $3 / 21(14 \%)$ & $3 / 21(14 \%)$ \\
Roots & Wisconsin & $2 / 2(100 \%)$ & $2 / 2(100 \%)$ \\
Tuber & Wisconsin & $18 / 56(31 \%)$ & $18 / 56(31 \%)$ \\
Tuber & Florida & $2 / 2(100 \%)$ & $2 / 2(100 \%)$ \\
\hline Other Sources & & $1 / 3$ & $2 / 3$ \\
\hline Water & Wisconsin & $3 / 11(27 \%)$ \\
FTA cards & Wisconsin & $5 / 11(45 \%)$ & \\
\hline
\end{tabular}

\section{Discussion}

In plant disease management, rapid, sensitive and accurate detection of pathogens is critical for timely responses that facilitate disease control. Furthermore, early disease detection is important for assessing plant health prior to seedling transplant. In this study, we developed a robust multiplex TaqMan real-time qPCR for simultaneous detection of all known Dickeya species and D. dianthicola in a single reaction. The primers were developed from unique and conserved genes, extracted using comparative genomic analyses of Dickeya species. The developed method has been thoroughly validated using strains in inclusivity and exclusivity panels as well as naturally and artificially infected samples. The method showed 100\% accuracy and successfully detected infection of both Dickeya species and D. dianthicola from infected plant samples received from different states of the United States.

Dickeya is one of the most important enteric soft rot pathogens known to cause tremendous economic losses worldwide. Dickeya species, especially D. dianthicola, is a major problem for potato growing countries, and therefore is included in the European Union A2 quarantine list of pathogens. Accurate detection, distribution and monitoring of this pathogen is critical for prevention of higher economic losses. Detection by culturing and isolation is time-consuming, especially when the pathogen can be overgrown by saprophytic bacteria commonly present in infected samples. PCR provides fast, robust and accurate detection of pathogens compared to traditional culture-based methods. Compared to traditional PCR, real-time qPCR allows faster, accurate, sensitive and quantitative monitoring of a pathogen with less chance of carry over contaminations (Arif et al. 2014, 2015; Strayer et al. 2016; Larrea et al. 2019). TaqMan real-time qPCRs have been developed for the detection of $D$. solani and D. dianthicola (Van Vaerenbergh et al. 2012; Pritchard et al. 2013), but these protocols have not been thoroughly validated. TaqMan qPCR assays for Dickeya species using the dnaX gene region have been reported by van der Wolf et al. (2014). However, the assay developed using $d n a X$ gene sequence for detection of $D$. solani was insufficiently specific and found not to be suitable for testing propagative material (van der Wolf et al. 2014). Therefore, the whole genome comparative genomics approach was used to develop robust primers and probe sets using highly unique and conserved genes. Multiplexing the reaction using different probes labeled with different fluorogenic dyes allows detection of multiple targets in a single reaction which facilitates rapid detection, reduces assay costs and enhances assay reliability (Arif et al. 2015; Larrea et al. 2019). The sensitivity and specificity of the developed 
assays depends on the target gene selection and the thermodynamics of the primers and probes (Arif and Ochoa Corona 2013).

During this study, comparative genomics identified unique region/gene in the target genomes of Dickeya species. We designed the primers from these target genes and their flanked region - this approach enhances the specificity and reliability of the developed assay since the gene arrangement among the strains within a species is conserved compared to strains from different species. The primers were selectively tested both in-silico, by searching for the homology in the nucleotide database (NCBI GenBank BLASTn), and in-vitro, by screening against the strains present in inclusivity and exclusivity panels (Table 1). Using BLASTn, the primers and probes were found to be specific for the target pathogen with $100 \%$ identity match and query coverage. No false negatives or false positives were observed during the validation. In our lab, the alcohol dehydrogenase gene was also used to develop a loop-mediated isothermal amplification assay for specific, on-site detection of $D$. dianthicola and proved to be highly specific (Ocenar et al. 2019).

Previously, we have demonstrated that incorporation of flap sequences at the 5 ' position of the primer could lead to increased sensitivity, fluorescence, overall PCR yield and optimize reaction efficiency (Arif and Ochoa-Corona 2013; Larrea et al. 2019). The 5' AT-rich flap sequences were added to both primers sets, DICg F1/R1 and Ddia F1/R1, to evaluate their effects on sensitivity and/or specificity of the developed assay. Both primers with and without 5' AT-rich flap sequences, targeting the Dickeya species and $D$. dianthicola, were specific for respective pathogens; no cross-reactions were observed (data not shown). Both multiplex primer sets, DICg F1/R1wf and Ddia F1/R1wf, with 5' AT-rich flap showed optimum reaction efficiency compared to the primers with no flaps (Figure 5) and were sufficiently sensitive to detect the genomic DNA of $D$. dianthicola and Dickeya species down to $10 \mathrm{fg}$. However, primers with no flap showed some discrepancy among the replicates at the lowest concentration $(10 \mathrm{fg}$; DICg F1/R1). Therefore, both primers with the 5' flap sequences were used for overall validation of the developed multiplex TaqMan qPCR assay. The addition of the 5' AT-rich flap also made the primers and probes compatible to mix and match based on user's need without losing specificity and/or sensitivity; these primers work under the "One Lab - One Protocol" concept (Arif 2019).

Multiplexing for specific detection of multiple targets in a single reaction is time efficient, provides enhanced reliability and further validation of the outcomes (Li et al. 2017). The probes labelled with internal ZEN quencher along with the traditional 3'end quencher enhance quenching efficiency, provide less background noise and increase precision (Arif et al. 2013). Multiplexing the reaction with different primer and probe sets can adversely affect the sensitivity and can increase the background noise ( $\mathrm{Li}$ et al. 2017). However, the developed assay did not show any discrepancy in the detection limit when assays were performed individually as compared to the multiplex reaction; both detected $10 \mathrm{fg}$ of genomic DNA. The presence of plant DNA mixed with pathogen DNA has been reported to interfere with the Taq DNA polymerase due to the presence of strong DNA-binding domains, reducing Taq-polymerase availability and activity, which results in higher Ct values (Hoy et al. 2001; Strayer et al. 2016). Therefore, the spiked assays were performed by adding the DNA from healthy plants along with target pathogen DNA in the multiplex qPCR reaction. No adverse effect on the $\mathrm{Ct}$ values was observed - the detection limit remained the same (10 fg) as with the pure genomic DNA from $D$. dianthicola. The genome size of Dickeya species ranges from 4.62-5.05 Mb (supplementary Table 1). Based on the calculations, $10 \mathrm{ng}$ of $D$. dianthicola genomic DNA contains $1.93 \times 10^{6}$ copies, therefore, $10 \mathrm{fg}$ should be equivalent to $\sim 2$ copies. The sensitivity of the developed multiplex TaqMan qPCR is higher (10 
fg per reaction; $\mathrm{Ct}=33.75 \pm 0.24$ compared to the previously reported primers/assays by Potrykus et al. (2014) for Dickeya species (detection limit 10 pg per microlitre) and van der Wolf et al. (2014) for $D$. dianthicola (20 fg per reaction; $\mathrm{Ct}=36.5 \pm 0.38$ ).

The effectiveness and robustness of any developed method is accessed by its ability to detect the pathogen from naturally infected samples. Therefore, the developed assay was tested with twentyfour asymptomatic and symptomatic, naturally infected plant samples. Thirteen samples showed positive amplification in both yellow and green channels, confirming the presence of $D$. dianthicola. Each infected sample that tested positive with TaqMan qPCR assay was further confirmed by sequencing the dnaA gene region followed by BLASTn (data not included). The BLASTn results confirmed $100 \%$ identity match with $D$. dianthicola. Furthermore, the developed method was also tested with 143 different plant and water samples received from various locations by the Wisconsin Potato certification laboratory. The method was able to detect 61 samples positive for Dickeya species and 60 for D. dianthicola. The developed method demonstrated the ability to be used for monitoring Dickeya species and $D$. dianthicola infections in naturally infected plant samples.

In conclusion, we developed a highly sensitive, robust, accurate, reproducible and specific multiplex TaqMan qPCR based on the whole genome comparative genomics approach, to simultaneously detect Dickeya species and $D$. dianthicola. To our knowledge, this is the only multiplex TaqMan qPCR to simultaneously detect genus Dickeya and $D$. dianthicola. The potato industry involves the global exchange of plant propagative materials; this tool will allow diagnosticians and certification agencies/labs to quickly test and identify the pathogen from pure culture and/or infected plant samples to prevent the dissemination of the disease to uninfected areas. Practical applications of the developed assay were demonstrated in rapid and large-scale screening of potato samples for certification purposes. This tool can also be utilized for the phytosanitary, disease epidemiology and management purposes.

\section{Acknowledgments}

This work was supported by the USDA National Institute of Food and Agriculture, Hatch project 9038H, managed by the College of Tropical Agriculture and Human Resources, and USDA FARMBILL (project number: APP-7058). The strains used in this study were revived and characterized with grant support from the National Science Foundation (NSF-CSBR grant no. DBI-1561663). The mention of trade names or commercial products in this publication does not imply recommendation or endorsement by the University of Hawaii. The findings and conclusions in this publication are those of the authors and should not be construed to represent any official USDA or U.S. Government determination or policy. This research was supported in part by the U.S. Department of Agriculture, Animal and Plant Health Inspection Service.

\section{Supplementary Materials}

Supplementary Table 1. Details of genomes used for target gene selection for development of TaqMan qPCR for specific detection of the Genus Dickeya.

\section{Conflicts of Interest}


The authors declare that they have no conflicts of interest.

\section{References}

1. Alikhan, N.F., Petty, N.K., Ben Zakour, N.L. and Beatson, S.A. (2011) BLAST Ring Image Generator (BRIG): Simple prokaryote genome comparisons. BMC Genom 12.

2. Arif, M. (2019) One lab-one protocol: synergetic effect of 5'AT-rich flap to harmonize qPCR protocols for easy, sensitive and cost-effective diagnostics. https://apsnet.confex.com/apsnet/2019/meetingapp.cgi/Paper/13274.

3. Arif, M., Aguilar-Moreno, G.S., Wayadande, A., Fletcher, J. and Ochoa-Corona, F.M. (2014) Primer modification improves rapid and sensitive in vitro and field-deployable assays for detection of high plains virus variants. Appl Environ Microbiol 80, 320-327.

4. Arif, M., Opit, G., Mendoza-Yerbafría, A., Dobhal, S., Li, Z., Kučerová, Z, et al. (2015) Array of synthetic oligonucleotides to generate unique multi-target artificial positive controls and molecular probe-based discrimination of Liposcelis Species. PLoS ONE 10, e0129810.

5. Arif, M. and Ochoa-Corona, F.M. (2013) Comparative assessment of 5' A/T-rich overhang sequences with optimal and sub-optimal primers to increase PCR yields and sensitivity. Mol Biotechnol 55, 17-26.

6. Boluk, G. and Arif, M. (2019) First report of Dickeya dianthicola as a causal agent of bacterial soft rot of potato in Hawaii. Plant Dis doi.org/10.1094/PDIS-11-18-2094-PDN

7. Brady, C.L., Cleenwerck, I., Denman, S., Venter, S.N., Rodríguez-Palenzuela, P., Coutinho, T.A., De Vos, P. (2012) Proposal to reclassify Brenneria quercina (Hildebrand and Schroth 1967) Hauben et al. 1999 into a new genus, Lonsdalea gen. nov., as Lonsdalea quercina comb. nov., descriptions of Lonsdalea quercina subsp. quercina comb. nov., Lonsdalea quercina subsp. iberica subsp. nov. and Lonsdalea quercina subsp. britannica subsp. nov., emendation of the description of the genus Brenneria, reclassification of Dickeya dieffenbachiae as Dickeya dadantii subsp. dieffenbachiae comb. nov., and emendation of the description of Dickeya dadantii. Int J Syst Evol Micr 62,1592-1602.

8. Buttimer, C., McAuliffe, O., Ross, R.P., Hill, C., O’Mahony, J. and Coffey, A. (2017) Bacteriophages and bacterial plant diseases. Front Microbiol 8, 34. doi: 10.3389/fmicb.2017.00034.

9. Czajkowski, R., Grabe, G. and van der Wolf, J.M. (2009) Distribution of Dickeya spp. and Pectobacterium carotovorum subsp. carotovorum in naturally infected seed potatoes. Eur J Plant Pathol 125, 263-275.

10. Czajkowski, R., Ozymko, Z., Zwirowski, S. and Lojkowska, E. (2014) Complete genome sequence of a broad-host-range lytic Dickeya spp. bacteriophage $\phi$ D5. Arch Virol 159, 3153-3155.

11. Czajkowski, R., Pérombelon, M.C.M., Jafra, S., Lojkowska, E., Potrykus, M., van der Wolf, J.M. and Sledz, W. (2015) Detection, identification and differentiation of Pectobacterium and Dickeya species causing potato blackleg and tuber soft. Ann App Biol 166, 18-38.

12. Darling, A.E., Mau, B. and Perna, N.T. (2010) Progressivemauve: Multiple genome alignment with gene gain, loss and rearrangement. PLoS ONE 5.

13. Dobhal, S., Larrea-Sarmiento, A., Alvarez, A.M. and Arif, M. (2018) Development of a loop-mediated isothermal amplification assay for specific detection of all known 
subspecies of Clavibacter michiganensis. J Appl Microbiol 126, 388-401 doi: 10.1111/jam.14128

14. Felsenstein, J. (1985) Confidence Limits on Phylogenies: An approach using the bootstrap Author (s): Joseph Felsenstein Published by: Society for the Study of Evolution Stable. Evolution (N. Y) 39, 783-791.

15. Hélias, V., Hamon, P., Huchet, E., Wolf, J.V.D. and Andrivon, D. (2012) Two new effective semiselective crystal violet pectate media for isolation of Pectobacterium and Dickeya. Plant Pathol 61, 339-45. http://dx.doi.org/10.1111/j.1365-3059.2011. 02508.x.

16. Hoy, M.A., Jeyaprakash, A. and Nguyen, R. (2001) Long PCR is a sensitive method for detecting Liberibacter asiaticum in parasitoids undergoing risk assessment in quarantine. Biological Control 22, 278-287.

17. Hyman, L.J., Sullivan, L., Toth, I.K. and Perombelon, M.C.M. (2001) Modified crystal violet pectate medium (CVP) based on a new polypectate source (Slendid) for the detection and isolation of soft rot erwinias. Potato Research 44, 265-70. http://dx.doi.org/10. 1007/BF02357904.

18. Kumar, S., Stecher, G., Li, M., Knyaz, C. and Tamura, K. (2018) MEGA X: Molecular Evolutionary Genetics Analysis across computing platforms. Mol Biol and Evol 35, 15471549.

19. Larrea-Sarmiento, A., Dhakal, U., Boluk, G., Fatdal, L., Alvarez, A.M., Strayer-Scherer, A., Paret, M., Jones, J., Jenkins, D. and Arif, M. (2018) Development of a genomeinformed loop-mediated isothermal amplification assay for rapid and specific detection of Xanthomonas euvesicatoria. Sci Rep 8,14298. https://doi.10.1038/s41598-018-32295-4

20. Larrea-Sarmiento, A., Alvarez, A.M., Stack, J.P. and Arif, M. (2019) Synergetic effect of non-complementary 5' AT-rich sequences on the development of a multiplex TaqMan realtime PCR for specific and robust detection of Clavibacter michiganensis and $C$. michiganensis subsp. nebraskensis. PLoS ONE 0218530. https://doi.org/10.1371/journal.pone.

21. Laurila, J., Ahola, V., Lehtinen, A., Joutsjoki, T., Hannukkala, A., Rahkonen, A. et al. (2008) Characterization of Dickeya strains isolated from potato and river water samples in Finland. Eur J Plant Path 122, 213-225. https://doi 10.1007/s10658-008-9274-5.

22. Li, B., Liu, H. and Wang W. (2017) Multiplex real-time PCR assay for detection of Escherichia coli $\mathrm{O} 157: \mathrm{H} 7$ and screening for non-O157 Shiga toxin-producing E. coli. BMC Microbiol 17, 215. http:// doi:10.1186/s12866-017-1123-2.

23. Ma, B., Hibbing, M.E., Kim, H-S., Reedy, R.M., Yedidia, I. et al. (2007) Host range and molecular phylogenies of the soft rot enterobacterial genera Pectobacterium and Dickeya. Phytopathology 97, 1150-1163.

24. Mansfield, J., Genin, S., Magori, S., Citovsky, V., Sriariyanum, M., Ronald, M., Dow, M.A.X., Verdier, V., Beer, S.V., Machado, M.A., Toth, I.A.N., Salmond, G. and Foster, G.D. (2012) Top 10 plant pathogenic bacteria in molecular plant pathology. Mol Plant Pathol 13, 614-629.

25. Motyka, A., Zoledowska, S., Sledz, W. and Lojkowska, E. (2017) Molecular methods as tools to control plant diseases caused by Dickeya and Pectobacterium spp: A minireview. New Biotechnol 39, 181-189.

26. Muhire, B.M., Varsani, A., Martin, D.P. (2014) SDT: A virus classification tool based on Pairwise Sequence Alignment and Identity Calculation. PLoS ONE 9, e108277. https://doi:10.1371/journal.pone.0108277. 
27. Norman, D. and Alvarez, A. (1989) A rapid method for presumptive identification of Xanthomonas campestris pv. dieffenbachiae and other Xanthomonas. Plant Dis 73, 654658. https://doi.org/10.1094/pd-73-0654.

28. Ocenar, J., Arizala, D., Boluk, G., Dhakal, U., Gunarathne, S., Paudel, S., Dobhal, S. and Arif, M. (2019) Development of a robust, field-deployable loop-mediated isothermal amplification (LAMP) assay for specific detection of potato pathogen Dickeya dianthicola targeting a unique genomic region. PLoS ONE 14, e 0218868.

29. Ouyang, P., Arif, M., Fletcher, J., Melcher, U., Ochoa Corona, F.M. (2013) Enhanced reliability and accuracy for field deployable bioforensic detection and discrimination of Xylella fastidiosa subsp. pauca, causal agent of citrus variegated chlorosis using Razor Ex technology and TaqMan quantitative PCR. PLoS ONE 8, e81647. https://doi.org/10.1371/journal.pone.0081647

30. Parkinson, N., DeVos, P., Pirhonen, M. and Elphinstone, J. (2014) Dickeya aquatica sp. nov., isolated from waterways. Int J Syst Evol Micr 64, 2264-2266.

31. Pritchard, L., Humphris, S., Saddler, G.S., Parkinson, N.M., Bertrand, V., Elphinstone, J.G. et al. (2013) Detection of phytopathogens of the genus Dickeya using a PCR primer prediction pipeline for draft bacterial genome sequences. Plant Pathol 62,587-596.

32. Raoul des Essarts, Y, Cigna, J., Quêtu-Laurent, A., Caron, A., Munier, E., Beury-Cirou, A., et al. (2016) Biocontrol of the potato blackleg and soft rot diseases caused by Dickeya dianthicola. Appl Environ Microbiol 82, 268 -278. https://doi:10.1128/AEM.02525-15.

33. Rozen, S. and Skaletsky, H.J. (2000) Primer3 on the www for general users and for biologist programmers. In Krawetz, S. \& Misener, S. (Eds), Bioinformatics methods and protocols: Methods in Molecular Biology (pp. 365-386). Totowa, NJ: Humana Press.

34. Saitou, N. and Nei M. (1987) The neighbor-joining method: A new method for reconstructing phylogenetic trees. Mol Biol Evol 4, 406-425.

35. Samson, R., Legendre, J., Christen, R., Fischer-Le Saux, M., Achouak, W. et al. (2005) Transfer of Pectobacterium chrysanthemi (Burkholder et al. 1953) Brenner et al. 1973 and Brenneria paradisiaca to the genus Dickeya gen. nov. as Dickeya chrysanthemi comb. nov. and Dickeya paradisiaca comb. nov. and delineation of four novel species, Dickeya dadantii sp. nov., Dickeya dianthicola sp. nov., Dickeya dieffenbachiae sp. nov. and Dickeya zeae sp. nov. Int J Syst Evol Micr 55, 1415-1427.

36. Strayer, A., Jeyaprakash, A., Minsavage, G.V., Timilsina, S., Vallad, G.E., Jones, J.B. et al. (2016) A multiplex real-time PCR assay differentiates four Xanthomonas species associated with bacterial spot of tomato. Plant Dis 100, 1660-1668

37. Tamura, K. and Nei, M. (1993) Estimation of the number of nucleotide substitutions in the control region of mitochondrial DNA in humans and chimpanzees. Mol Biol Evol 10, 512526.

38. Tian, Y., Zhao, Y., Yuan, X., Yi, J., Fan, J., Xu, Z. et al. (2016) Dickeya fangzhongdai sp. nov., a plant pathogenic bacterium isolated from pear trees (Pyrus pyrifolia). Int J Syst Evol Micr 66, 2831-2835.

39. Tsror (Lahkim), L., Erlich, O., Lebiush, S., Hazanovsky, M., Zig, U., Slawiak, M. et al. (2009) Assessment of recent outbreaks of Dickeya sp. (syn. Erwinia chrysanthemi) slow wilt in potato crops in Israel. Eur J Plant Path 123, 311-320. https://doi: 10.1007/s10658008-9368-0.

40. van der Wolf, J.M., Nijhuis, E.H., Kowalewska, M.J., Saddler, G.S., Parkinson, N., Elphinstone, J.G. et al. (2014) Dickeya solani sp. nov., a pectinolytic plant-pathogenic 
bacterium isolated from potato (Solanum tuberosum). Int J Syst Evol Micr 64:768-774. 41. Van Vaerenbergh, J., Baeyen, S., De Vos, P. and Maes, M. (2012) Sequence diversity in the Dickeya fliC gene: phylogeny of the Dickeya Genus and TaqMan ${ }^{\circledR}$ PCR for 'D. solani', New Biovar 3 Variant on Potato in Europe. PLoS ONE 7, e35738. 